\title{
Results of Using the Take-away Technique on Students' Achievements and Attitudes in High School Physics and Physical Science Courses
}

\author{
James Carifio $^{1} \&$ Michael Doherty ${ }^{1}$ \\ ${ }^{1}$ Graduate School of Education, University of Massachusetts-Lowell, Lowell, USA \\ Correspondence: James Carifio, Graduate School of Education, University of Massachusetts-Lowell, Lowell, \\ MA 01854, USA. E-mail: James_Carifio@uml.edu
}

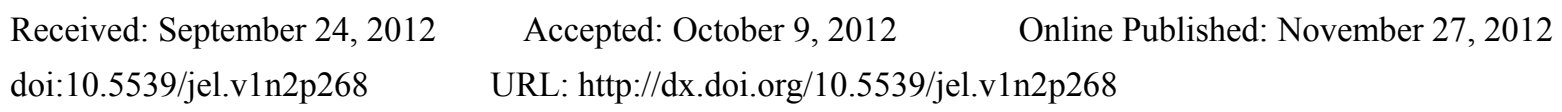

\begin{abstract}
The Take-away Technique was used in High School Physics and Physical Science courses for the unit on Newtonian mechanics in a teacher (6) by grade level (4) partially crossed design ( $\mathrm{N}=272)$. All classes received the same IE instructional treatment. The experimental group (classrooms) did a short Takeaway after each class summarizing the key concepts and points covered in the class, whereas the control group (classrooms) wrote a short evaluation of what they liked and disliked about the class. The experimental group performed better than the control group on the standardized Force Concepts Inventory achievement measure (Hestenes et al., 1992) using Hake normalized gain scores by a quarter to two-thirds of a standard deviation. Neither group showed the typical decline in attitudes towards Physics that occurs in IE approaches. The experimental group students gave the same positive benefits for the Takeaway technique as given in a previous study done with college undergraduates in a psychology course with those students in the control group citing much lower rates of these benefits and primarily emotional expression benefits. Given its design, the increased achievement observed in this study could be attributed directly to the Take-away technique as opposed to other rival hypotheses.
\end{abstract}

Keywords: science instruction, high school physics, higher order learning, achievement enhancement, written summarizations, learning character, self-directed learning, anxiety optimization, meta-cognition, long-term memory formation

\section{Introduction}

\subsection{Theoretical Framework}

According to cognitive learning theory (i.e., Bruning et al, 2012; Ashcraft, 2001; and Schunk, 2011), the back-end of the learning process would be processes, activities and assignments that organize, elaborate, consolidate, connect, and incorporate what the student should be taking away from an (instructional) exchange or event into the student's long term memory. However, cognitive theory also contends that all of these back-end learning processes should not be prescriptive (namely, done by the instructor or the instructional agent), but rather that they should be actively done by the student and should be $a$ well established meta-cognitive student habit; namely, a continuously cognitively active and self-regulated learner (see Zimmerman, 1994; Green \& Azvendo, 2007; and Dinsmore et al., 2008 for details). This view of learning and instruction has been characterized as learning as a do-it-your-self project (with occasional guidance and high quality feedback) and learning in spite of things, difficulties, obstacles and the environment, or more succinctly, learning character (see Eagle, 1997; Reivich \& Shatte 2002; and Carifio, 2005 and 2010 for details). Various aspects, components, and dimensions of this theoretical view, moreover, are present in the works of Spielberger (1972), Ausubel (1976), Meier \&Seligman (1976), Vygotsky (1978), Mandler, (1989), Erikson (1993), Dagostino and Carifio, (1994), Kintch (1998), Neisser and Hyman, (1999), Pressley (2002), Meeter \& Murre, (2004), van Dijk (2006), and Pinker (2009), and each will be commented on in more detail below where necessary. The Take-away Technique is one (highly versatile) way of operationalizing this view and theory as part of any formal or informal learning event or informational exchange. The cognitive/instructional Take-away Technique was devised by Carifio (2010) and is more fully explained in his 2010 article. 


\section{Method}

\subsection{The Take-away Technique}

The Take-away Technique is the component of an instructional system that develops a student's Take-away skills and habits. The cognitive theory view of the take-way technique, therefore, focuses on the student actively extracting and creating the meanings and messages of the exchange rather than "zoning out" and passively waiting to be told what the meaning and messages of the presentation or exchange were or are (see Carifio, 2010 for details). The student must figure out and create the "gist" of the meanings and messages in the exchange and then must formulate them into a form that can be communicated to others. It is the student who must actively organize and sort out the meanings and the messages and elaborate them and organize them into wholes and schemas that may be expressed to others and thus into a form that is more amenable to being incorporated into long term memory. Recent research, moreover, has shown that elevated but optimized anxiety levels in students during learning greatly facilitate and maximize long term memory formation for the materials being learned (see Meeter \& Murre, 2004 for details). Elevated but optimized anxiety levels during learning and particularly in the back end of the learning process, consequently, is a good and not a bad thing, as it enhances the formation and strengthening of the learner's long term memory structures. The cognitive learning theory form of the take-way, therefore, intentionally acts to inhibit student passivity and learned helplessness (see Meier \& Seligman, 1976 for details), as it transfer the responsibility and task of extracting and organizing the meanings and messages of a presentation or exchange to the student, and makes the student actively do these key cognitive tasks and processes and actively practice them with each exchange. The Take-away technique, therefore, focuses on building learning character and responsibility (see Reivich \& Shatte, 2002 for details), and cognitive learning theory predicts that student learning, and particularly higher order learning, should increase over time through being actively responsible for and engaging in these key back-end processes (see Kintch, 1998; and van Dijk, 2006 for details).

\subsection{Initial Results}

The "take-away" technique was initially tested in an undergraduate cognitive psychology class at a public university in New England with 33 students (see Carifio, 2010 for details). The students were given the assignment of producing a one-page written summary (the minimum) of what they considered to be the key points, exchanges, and messages of the 90 minute class that occurred twice a week within 24 hours of the class and to submit their "take-away" for the class to the instructor's teaching assistant. Completing the Take-away for the class counted for $20 \%$ of each student's grade, but students were purposefully given minimum feedback on the Take-aways in order to get an estimate of the effects of the Take-aways with minimal feedback and additional work by the instructor, and to keep the amount of additional instruction received by each student from the Take-aways at a minimum and roughly constant for each student. Any effects that were observed, therefore, would be the minimum baseline effects of using the Take-away Technique. A simple five point scoring rubric was used to provide each student with assignment completion feedback on the Take-away submitted that told them if it meet the minimum assignment requirements or not (stated above) and the Take-aways' overall quality on a one to seven point scale. This rubric was completed by the instructor's teaching assistant, and the instructor did not read any of the Take-aways from students until after the semester was completed for several different reasons, but also to establish a baseline of Take-away effects with classroom instruction not being atypically altered or changed due to the content of each classes Take-aways (see Carifio, 2010 for details).

There were 30 classes in the course, and the instructor sometimes lectured and sometimes engaged the students with Socratic questioning and various class activities directed at illustrating the tenants of cognitive psychology and cognitive learning theory. The course had three (3) written in-class exams on the readings assigned both before and after class, and the essay exams were spaced 5 weeks apart. The questions on the exams were questions that required the students to explain and elaborate course content, concepts, principles and theories and to relate aspects of course content together in their written responses. The exams also had one question that was an applications question that required higher order critical thinking. Several other factors were also built into this study and data were obtained on these students which consisted of GPA, Verbal SAT, Math SAT, and SAT writing sample scores. Lastly, a question on the final exam asked students to cite what they found positive about the Takeaways they had to write (and why) and what they found to be the negatives of writing Takeaways (and why), and what they would do to correct the negatives.

The quality of student Takeaways, using a simple scoring rubric, predicted essay exam achievement at $\mathrm{r}=+.45$ across the three exams with students being positive about the technique by the end of the course. Students' Math, Verbal, and Writing SAT scores did not predict the quality of the Takeaways they wrote (as predicted), or their scores (grades) on the 3 essay examinations in the course. Student evaluations of the Takeaway technique were 
congruent with both the model and theory of Take-aways developed, and students were quite astute about the Take-aways and their several functions by the end of the course. The quality of student responses to in-class essay exam questions improved remarkably over the semester with students' essay question responses becoming lengthier, more elaborated, coherent, sophisticated, and well written on each occasion, and particularly so for the higher order and more difficult essay questions (see Carifio, 2010 for details). Overall, the Takeaway technique proved to be a relative simple and flexible device and strategy that could be used in many different ways to develop students' cognitive and meta-cognitive skills and learning character, and higher order cognitive processes and understandings of subject-matter content, even though the technique has limitations and drawbacks which may be overcome in various ways. As predicted, the cognitive Takeaway was particularly successful with and helpful to students who were novices in the subject-matter to be learned. The results of this minimalist-baseline study were so positive that it was decided to scale-up and extend the exploratory testing of the Take-away technique, and in a manner that would also answer several currently outstanding questions about the learning of science in high school as well.

\subsection{The Current Study}

Using the results of the pilot study, the Take-away Technique was next investigated in suburban High School IE (Interactive Engagement) Physics and Physical Science courses for the unit on Newtonian mechanics. The suburban high school was large and in the Northeast section of the USA. The study involved 6 high school physics and physical science teachers and 274 ninth to twelfth grade students, and it focused on the students' understanding of Newtonian Mechanics using the Force Concepts Inventory (Hestenes, Wells, \& Swackhamer, 1992), the Mechanics Baseline Test (Hestenes \& Wells, 1992) [covariate)] and the Colorado Learning Attitudes about Science Survey (Adams et al., 2006) as measures of effects and covariates. These three instruments are the three instruments used in most studies on students' acquisition and understanding of Newtonian Mechanics reported in the American Journal of Physics and the Physics Teacher over the last fifteen years, and their reliabilities and validities are quite good. The Force Concepts Inventory and the Colorado Learning Attitudes about Science Survey were administered on a pre and post-test basis and the Mechanics Baseline Test and a background questionnaire were administered before the instructional unit only.

The Force Concept Inventory is typically scored using the Hake normalized gain score (see Hake, 1987; 1998a 1998b; and Coletta \& Phillips, 2005 for details) for reasons dealing with regression, scale discontinuities, and typically non-random assignment of students to instructional treatments (as in this study). A Hake normalized gain score is:

$$
\text { Hake gain }=\frac{\text { Post-instruction } \% \text {-Pre-instruction } \%}{100 \%-\text { Pre-instruction } \%}
$$

(reported as the average of the individual averages)

The norms for evaluating instructional effectiveness at facilitating Newtonian thinking using Hake gain scores is:

$$
\begin{array}{ll}
<30 \% & \text { Ineffective (Traditional Instruction Range) } \\
>30 \% \text { but }<70 \% & \text { Moderately Effective } \\
>70 \% & \text { Effective }
\end{array}
$$

It was also decided to use Hake scores for the Mechanics Baseline test and the Colorado Learning Attitudes about Science Survey so as to keep all data in the same metric and on the same scale while controlling for the problems the scoring procedure is designed to control.

There was an experimental and control group in this second study. However, classrooms rather than students were randomly assigned to the experimental and control treatments, and two of the teachers could only teach one course so they were randomly assigned to experimental or control classrooms.

\subsection{The Instructional Treatment}

IE Physics was developed to remediate misconceptions and facilitate conceptual understanding through interactive-engagement. IE Physics is based on a cognitive view of learning and emphasizes student involvement 
in discussions regarding concepts and understandings and students actively constructing their own understandings (Mestre, 1994). IE methodologies are more effective at facilitating conceptual gain (Mestre, 2005), and IE Physics significantly reduces performance gaps associated with gender (Lorenzo et al., 2006). IE gives instructors insight into student thinking (Redish, 1994), and IE approaches promote conceptual change through the construction of explanations (Hewson \& Hewson, 1984). IE approaches yield higher success rates (greater Hake gain score change percentages), and particularly for females and minorities, than traditional instruction approaches do (Beichner et al., 2007). However, IE methodologies require more time per unit resulting in content coverage loss with respect to traditional instruction which is a factor that sometimes impedes their adoption (Laws, 1991). Further, not a great deal is known about how using actual writing strategies of any kind would improve all of these Haake conceptual gain scores over current baselines in the literature, even though both the use and investigation of the effects of using writing strategies is constantly recommended (see Keys et al., 1999; Hubbs \& Brand, 2005; and Hautau et al., 2006 for details). Therefore, generating information on this unanswered question was ONE of the reasons for conducting this study. The other and more pertinent reason was to assess the effects the Take-away Technique would have with high school students and in the learning of science content.

For as yet unclear reasons, it should be noted, IE approaches to teaching Physics result in student attitudes towards science becoming significantly more negative (Crouch et al., 2007; Hestenes, \& Halloun, 1995; Redish et al., 1998; Adams et al., 2006; and Otero \& Gray, 2008). Therefore, in the current study, no significant attitude change is a positive outcome and improvement over what normally occurs as a result of IE instruction.

\subsection{The Experimental Treatment}

Both the experimental and control group in this study received the same IE instruction treatment (except from different teachers) that only differed in one respect. In the experimental group, students wrote a one-half to one page "bullets-form" Take-away (see Carifio, 2010 for details) for each class that summarized the key points relative to the concepts and principles that were covered in the class, whereas in the control group students wrote a one-half to one page evaluation of what they liked and disliked about the class, which was a "control" reflection and a "control" summarizing (experience) that also kept the amount of treatment received by each student constant. The unit on Newtonian mechanics was four weeks long.

The procedures for post-class writing assignments for the experimental and the control group in this study were quite similar to those used in the first study and for many of the same reasons. Completing the Take-away for the class counted for $20 \%$ of each student's grade, but students again were purposefully given minimum feedback on the Take-aways in order to get an estimate of the effects of the Take-aways with minimal feedback and additional work by the teacher, and to keep the amount of additional instruction received by each student from the Take-aways at a minimum and roughly constant for each student in the experimental group and particularly as compared to students in the alternative "likes and dislikes about the class" control group Further, if teachers started giving students in the experimental group feedback about their Take-aways, they would have to give students in the control group feedback concerning their "likes and dislikes" about each class which simply could not be done and would not be wise for several additional reasons.

The writing prompt given to students in the Take-away (experimental) treatment was:

Please list in sentence form what you considered to be the key and critical points (concepts, principles, ideas and so on) in what you read, discussed and experienced as part of today's class.

Your list should be one-half to one-page long at a minimum, and your points should use the vocabulary, terms and key concepts and principles that you have learned in the course up to and including today's class.

Each point on your list should be able to be read and understood by people/readers other than yourself.

The writing prompt given to students in the control (express your like and dislikes) treatment was:

Please list in sentence form what you liked and disliked about today's assignments and class.

Your list should be one-half to one-page long at a minimum.

Each point on your list should be able to be read and understood by people/readers other than yourself.

A simple four point scoring rubric was used to provide each student with assignment completion feedback on the Take-away or control writing assignment submitted that told them if it meet the minimum assignment requirements or not (stated above) and the teacher's overall quality assessment of their submission on a one to seven point scale. This rubric was completed by the student's teacher who was trained for a day before the study started on how to introduce and handle the Take-away and control writing assignments relative to responding to 
them minimally and not letting them influence or alter their teaching as best as they could. These teachers also kept a teaching log during the treatment. The second author of this article was also on site daily to supervise and work with these teachers relative to any questions or difficulties they had over the four week period relative to the treatments they were to implement, or with teaching IE Physics according to the Reformed Teaching Observational Protocol (Piburn, et al., 2000 and 2002) which assesses the degree to which IE Physics has been properly implemented in the teacher's classroom. Teachers in this study were observed twice by the second author of this article using the Reformed Teaching Observation Protocols and all teachers were found to be implementing IE Physics compliant classrooms at the minimally acceptable level with the more experience teachers doing so better than the less experienced teachers as would be expected. The second author of this article has taught IE Physics for over thirty years and has been certified to as an IE Physics teacher and was head of the science department at the school at which this study was conducted.

At the end of the unit, students completed an evaluation form which indicted the two things that they liked about the Take-away assignment they experienced and the two things they disliked about take-away assignment, which were the same two questions asked in the pilot study, so their results could be compared to the results of the pilot study reported above. The 6 teachers filled out a similar evaluation form and were interviewed about the positive and negatives they found in having students do the Take-aways.

\subsection{Coding Students Responses}

The positive and negative responses given by each student about the Take-away or Control technique were reviewed by 2 independent reviewers who proposed a set of categories for coding the reasons that were consonant with Take-away theory. A final set of both micro and macro categories were agreed upon by the reviewers, and then the two reviewer coded students' reasons using these categories and arbitrated any disagreements they had, which were less than $5 \%$ of the classifications. The two reviewers who coded student reasons in this study were different from the two reviewers who coded students' responses in the same way in the pilot study.

\section{Results}

The purpose of this article is to focus on the results obtained using the Take-away technique as opposed to the "control" technique in the learning of Newtonian mechanics, and students' qualitative understanding of and evaluations of the technique as compared to the "control" technique more than all of the other various questions inherent in this study about the "learning of Newtonian mechanics." Given this point, the first thing that must be ascertained (similar to the pilot study) is that the Take-away technique increases student achievement, and particularly higher order achievement, which is inherent in and measured by the instruments used.

Put simply, the experimental treatment (i.e., the Take-away technique) facilitated much greater Hake gain score percentage increases in conceptual understanding than the control treatment did (i.e., writing one's likes and dislikes about each lesson) as follows for the different major data breakdowns and subgroups in this study:

Table 1. Percentage of hake-score achievement gain for the take-away experimental group and the reflective writing control group overall and by subgroups in this study $(\mathrm{N}=274)$

\begin{tabular}{lll}
\hline Hake-score Gain Percentage for & Experimental Group & Control Group \\
\hline The entire study (all students) & $42 \%$ & $24 \%$ \\
The Physics sub-group & $67 \%$ & $38 \%$ \\
The Physical Science sub-group & $28 \%$ & $16 \%$ \\
The Honors Level sub-group & $50 \%$ & $34 \%$ \\
The Non-honors Level sub-group & $21 \%$ & $13 \%$ \\
\hline
\end{tabular}

All of the Hake gain score percentage differences presented in Table 1 are highly significant at greater than the .001 level and are effect sizes ranging .25 to .67 , which are large effect size differences. The sub-trends were that older students experienced greater gains than younger students (which could be attributed to having had more science as well as level of cognitive development) and Honors students experienced greater gains than Non-honors students (same). Also, gains were greater for experienced than non-experienced teachers. Using the pretest data, the 12 groups were not that dissimilar to begin with, but there were some differences between some classes at the .05 level even on the self-reported background questionnaire used. However, it should be 
remembered that the Hake normalized gain score is designed to control these difference and these (in this case, weak) effects.

The Mechanics Baseline Test predicted achievement gain scores significantly less in the experimental group than the control group $(\mathrm{r}=.21$ versus .48 , Fischer- $\mathrm{z}=3.14, \mathrm{p}<.001)$. Attitude scores declined less in the experimental group than in the control group, but neither the decline nor the differences were significant. This attitudinal outcome of significantly less [expected] loss in the Take-away group than the control group was a very positive outcome for the Take-away technique (see Otero \& Gray, 2008 for details).

All in all, the Take-away technique significantly improved achievement gains as compared to the control technique and because a control technique was used that was like but the antithesis of the take-away technique (a rival hypothesis and explanation), the improved achievement could attributed to the take away technique rather than simply reflection or writing or "journaling" as it is sometimes called. Therefore, the question of importance becomes, "How was the Take-away technique subjectively experienced and reported on by students?"

Analysis of Response Frequencies within the Positive and Negative Macro Categories established from the Student Exit Survey indicated that students perceived the experimental treatment (doing the Take-aways) as more beneficial to their academic success than the control treatment did of their post learning activity of evaluating their likes and dislikes of the class. As can be seen in Table 2 below, students who did the Take-aways saw them as enhancing targeted understanding, and enhancing their higher order learning at a 3 to 4 to 1 rate as compared to the control group who saw their evaluating likes and dislikes about the class as enhancing their emotional expression, which only 2 student in the Take-away group reported as a characteristic or benefit of the take-away.

Table 2. Frequency of students citing the primary predicted benefits of the treatment experienced in the take-away experimental group and the reflective writing control group $(\mathrm{N}=274)$

\begin{tabular}{lll}
\hline Benefits of Treatment Experienced Category & Experimental Group & Control Group \\
\hline Enhances Targeted Understanding & 95 & 27 \\
Enhances Higher Order Learning & 47 & 11 \\
Enhances Emotional Expression & 2 & 36 \\
No Benefit & 7 & 29 \\
\hline
\end{tabular}

The data in Table 2 above actually masks the magnitude of the differences between the experimental and control group to a significant degree. The amazing unexpected finding was that $25 \%$ of the students in the control group indicate in one form or another in their survey that they shifted over at some point during the four weeks from writing about their likes and dislike of the class to writing Take-aways for the class! It is unclear from the data collected as to how much of this shifting was due to talking to friends, teacher suggestions or just figuring out that it was a more productive way of using their time than the task that was assigned to them to do relative to learning and understanding Physics. So the control group numbers are "inflated" somewhat on the benefits side.

One of the easiest ways to quickly grasp the impact of the Take-away technique in this study and how different it was and was qualitatively as an experience for students is to look at the visual representation of the results given in Figures 1 (Positive Factors) and Figure 2 (Negative Factors) for the take-away and the Control group. The differential pattern of reasons and reasons as they relate to Take-away Theory is pronounced.

Figures 1 and 2 above allow one to quickly see visually how very different the response patterns and qualitative experiences were between the students who did Take-aways writing bullet summaries of their key learnings in the class and the students in the control group who wrote bullet summaries about their likes and dislikes of the class. Figures 1 and 2 also clearly show visually how writing Take-aways is not "reflective journaling" or journaling or "blogging" about the class and its events or the same type of activity cognitively or in terms of long term memory formation and strengthening, which is a very important point both practically and theoretically. Constructing and communicating meaningful summary understandings and elaborations of subject-matter content, and connecting these meaningful summaries together into logical wholes, is more than and quite different from reflection, opinions, feelings, and personal insights about the subject matter content expressions, and it has a direct and much greater impact on learning, memory and achievement than these alternative "writing 
activities," as is clear from the data in this study. The Take-away technique is not journaling or reflective writing and is in fact very different from these activities and should not be confused with them.

Table 3 presents the comparisons of the Take-away and control group's positive and negative points by micro-category so that the fine grained points and details that students reported for the positives and negatives of the Take-away technique can be compared to those of the control technique. The responses of these 271 high school students learning science content can then compared to the positive and negative points about the Take-away technique given by university students in a social science course in the Pilot study (Tables 4 and 5). These tables, it should be noted, enumerate specifically and at a very detailed level the general cognitive behaviors and skills Take-aways facilitate and develop, as well as their key short-comings and limitations currently, each of which is explained in detail and connected more specifically to Take-away theory in Carifio (2010). One can quickly develop a fairly good and concrete understanding of Take-aways and how they function and why they work from reading and studying Tables 3, 4, and 5.

The fine grain positive points about the benefits of the Take-away technique given in Tables 3 and 4 agree with each other and with the theoretical benefits of the Take-away technique as stated in detail in the article that reported the results of the pilot study (Carifio, 2010) and in this article as well. The only result that was truly startling and surprising was the frequency that high school student reported having memory problems and problems remembering the content that they were studying, which really needs further investigation for a number of reasons, including performance and achievement problems and the factors that could be causing these reported memory difficulties including possible developmental problems (see Schneider \& Pressley, 1997 for details).
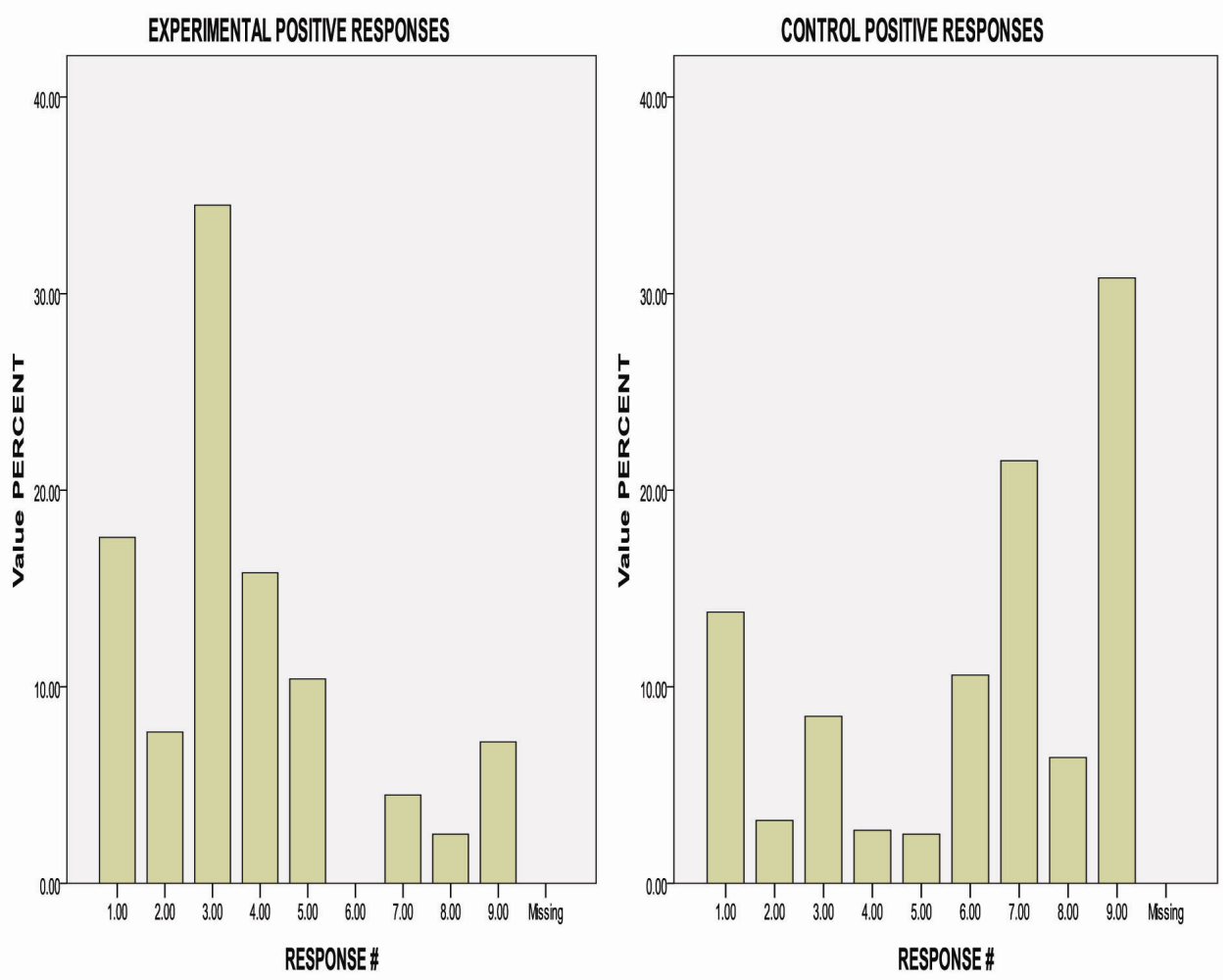

Figure 1. Positive response frequencies by treatment type

Note. Response Number Key:

1. Enhances Reviewing Targeted Content (including review of problems \& labs for tests) 2. Enhances Academic/Study/Science Writing Skills (includes developing discipline \& memory skills) 3. Enhances Understanding Targeted Content 4. Enhances Higher Order Learning (includes thinking, application, \& question generation) 5. Enhances Memory/Retention Targeted Content 6. Enhances Emotional Expression 7. Other (including untargeted review/easy grade) 8. None 9. Response Left Blank 

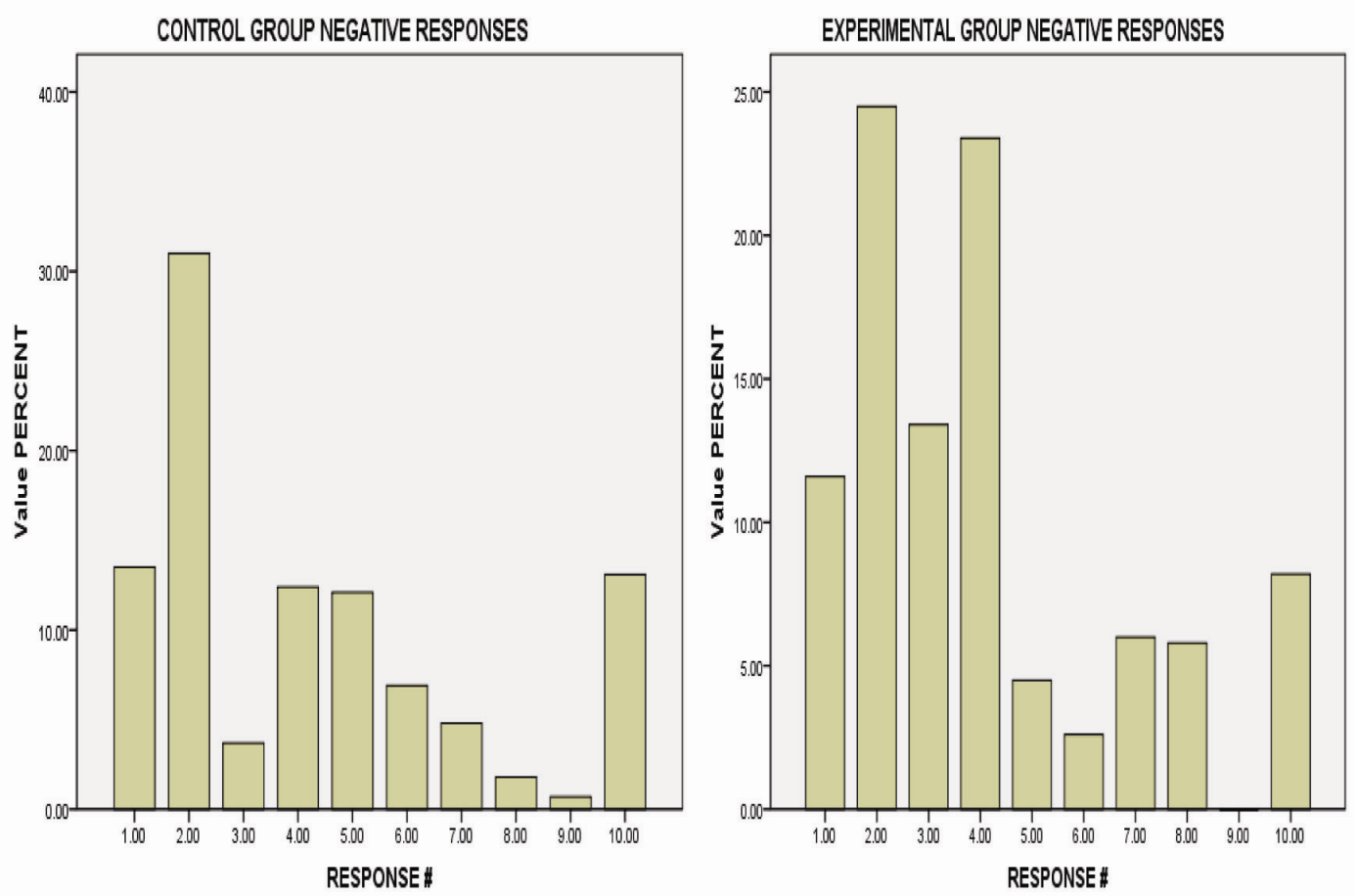

Figure 2. Negative response frequencies by treatment type

Note. Response Number Key:

1. Memory Problems/Blanking 2. Tedious, Boring, Monotonous 3. Pace of Instruction (too fast/too slow) 4. Cognitive/Homework Load of Task 5. Not Relative to Leaning/Useless 6. Privacy/Grading Issues 7. Lack of Skills to Do Task 8. Other (including reduced instructional time) 9. None 10. Left Blank

A very important finding that emerged from this second study that was not found in the first study was that most female students were extremely positive about the Takeaways and doing them and felt that the Takeaways made science more "female friendly" and less "problem working and problem solutions" oriented, which made the module and the evaluation of what was learned more equitable in their view. Many male students, on the other hand, felt that the Take-aways were inappropriate and that they should not have to express their understanding of Physics in writing (Physics was about "working the problems and doing the math" as more than one male student wrote). Female students in the Take-away group had significantly highly achievement than the females and the males in the control group as well. This disordinal interaction was pronounced and present in all of the analyses done of this data. This set of findings support several speculative hypotheses that have been stated by other researchers in this area previously about the possible benefits that a more verbal orientation to instruction and assessment procedures in science might have for female students (see Keys et al., 1999; Hubbs \& Brand, 2005; and Hautau et al., 2006). Teachers also listed the same benefits for the Take-aways as students, and said that the extra work of doing the Take-aways was worth it for the improved student performance they observed. However, they wished that there were procedures for more refined analyses of what students wrote and for automating the process of scoring the Take-aways, as well as making Take-aways less labor intensive for (high school) students. 
Table 3. Reduced macro categories frequencies for coding students' positive and negative comments about take-aways for both experimental and control groups $(\mathrm{N}=271)$

\begin{tabular}{|c|c|c|c|c|c|c|}
\hline \multirow[t]{2}{*}{ Macro Categories for Positives of doing Takeaways } & \multicolumn{3}{|c|}{ Experimental } & \multicolumn{3}{|c|}{ Control } \\
\hline & P1 & $\mathbf{P 2}$ & Total & P1 & $\mathbf{P 2}$ & Total \\
\hline Enhances Reviewing Targeted Content & 26 & 24 & 50 & 32 & 10 & 42 \\
\hline $\begin{array}{l}\text { Enhances Academic/Study/Science Writing Skills } \\
\text { (developing discipline and memory skills) }\end{array}$ & 3 & 8 & 11 & 3 & 9 & 12 \\
\hline Enhances Understanding Targeted Content & 79 & 16 & 95 & 18 & 19 & 27 \\
\hline $\begin{array}{l}\text { Enhances Higher Order Learning } \\
\text { (includes thinking, application, \& question generation) }\end{array}$ & 6 & 41 & 47 & 1 & 10 & 11 \\
\hline Enhances Retention Targeted Content & 9 & 21 & 30 & 7 & 4 & 11 \\
\hline Enhances Emotional Expression & 0 & 2 & 2 & 18 & 18 & 36 \\
\hline Other (easy grade \& untargeted reviewing) & 5 & 8 & 13 & 43 & 26 & 69 \\
\hline None & 6 & 1 & 7 & 15 & 14 & 29 \\
\hline Negatives of Doing Takeaways & N1 & N2 & Total & N1 & $\mathbf{N 2}$ & Total \\
\hline Memory Problems/Blanking & 12 & 19 & 31 & 17 & 20 & 37 \\
\hline Tedious/Boring/Monotonous & 58 & 9 & 65 & 68 & 15 & 83 \\
\hline Pace of Instruction (too fast/too slow) & 12 & 24 & 36 & 3 & 7 & 10 \\
\hline Cognitive/Homework Load of Task & 29 & 31 & 60 & 17 & 19 & 36 \\
\hline Not Relevant to Learning/Useless & 6 & 6 & 12 & 17 & 16 & 33 \\
\hline Privacy/Grading Issues & 4 & 3 & 7 & 5 & 14 & 19 \\
\hline Lack of Skills to Do Task & 5 & 11 & 16 & 6 & 7 & 13 \\
\hline $\begin{array}{l}\text { Other } \\
\text { (including reduced instructional time) }\end{array}$ & 7 & 12 & 19 & 2 & 3 & 5 \\
\hline None & 0 & 0 & 0 & 2 & 0 & 2 \\
\hline
\end{tabular}

Note. $\mathrm{P} 1$ = first positive comment listed, $\mathrm{P} 2=$ second positive comment listed

$\mathrm{N} 1=$ first negative comment listed, $\mathrm{N} 2=$ second negative comment listed

Table 4. Student-generated positive aspects and outcomes of doing takeaways rated by consonance with takeaway theory in the first 2010 study ( $\mathrm{N}=30$ college students)

\begin{tabular}{lllllll}
\hline Student Ranking of Point & $\mathbf{1}$ & $\mathbf{2}$ & $\mathbf{3}$ & $\mathbf{4}$ & Totals & Ratings \\
\hline 1. STUDY SKILLS & & & & & $\mathbf{1 7}$ & \\
11. Required students to read (text/articles) & 1 & 0 & 0 & 0 & 1 & 5 \\
12. Prepare prior to Lecture & 0 & 1 & 0 & 0 & 1 & 5 \\
13. Focus during Lecture & 2 & 0 & 0 & 0 & 2 & 5 \\
14. Note-taking skills improved & 0 & 1 & 0 & 0 & 1 & 4 \\
15. Required Learning: & 0 & 1 & 1 & 0 & 2 & 4 \\
$\quad$ Time Management/Meta-cognition & 1 & 1 & 0 & 0 & 2 & 4 \\
16. Increased academic Confidence & 0 & 0 & 1 & 0 & 1 & 5 \\
17. Overcoming academic obstacles & 0 & 0 & 2 & 0 & 2 & 4 \\
18. Attendance increased & 0 & 1 & 2 & 0 & 3 & 4 \\
19. Learning to learn from emails, peers, other & & & & & & \\
\hline
\end{tabular}




\begin{tabular}{lllllll} 
20. Application of new skills to other classes & 0 & 0 & 0 & 1 & 1 & 4 \\
21. Easy Grade & 0 & 0 & 1 & 0 & 1 & 1 \\
2. COMPREHENSION SKILLS & & & & & $\mathbf{4 9}$ & \\
22. Organizing Info to makes sense of info & 8 & 6 & 3 & 0 & 17 & 5 \\
$\begin{array}{l}\text { 23. Making connections reading/Life } \\
\text { /lecture/concepts }\end{array}$ & 2 & 4 & 5 & 3 & 15 & 5 \\
24. Revising and learning from Feedback from TA & 0 & 3 & 2 & 3 & 8 & 4 \\
25. Interesting, Creates desire to learn more & 0 & 2 & 1 & 0 & 2 & 5 \\
26. Increased depth and ways of thinking, elaborating & 1 & 1 & 2 & 3 & 7 & 5 \\
3. RETENTION ( TEST TAKING SKILLS) & & & & & $\mathbf{3 1}$ & \\
27. Organizing notes for clear, concise Study Review & 1 & 6 & 3 & 0 & 10 & 4 \\
28. Rewriting, Repetition & 11 & 0 & 3 & 2 & 16 & 5 \\
29. Discovering best study format for self & 1 & 0 & 0 & 1 & 3 & 3 \\
30. Less Exam stress & 0 & 0 & 0 & 2 & 2 & 4 \\
4. WRITING SKILLS & & & & & $\mathbf{1 1}$ & \\
31. Practice & 0 & 2 & 2 & 1 & 5 & 5 \\
32. Speed & 1 & 0 & 0 & 0 & 1 & 4 \\
33. Redoing notes into structured form & 1 & 1 & 1 & 1 & 4 & 4 \\
34. Feedback from TA improved writing skills & 0 & 0 & 1 & 0 & 1 & 3 \\
& $\mathbf{3 0}$ & $\mathbf{3 0}$ & $\mathbf{3 0}$ & $\mathbf{1 7}$ & $\mathbf{1 0 8}$ & \\
\hline
\end{tabular}

Table 5. Student-generated negative aspects and outcomes of doing takeaways rated by consonance with takeaway theory for the first 2010 study ( $\mathrm{N}=30$ college students)

\begin{tabular}{lllllll}
\hline Student Ranking of Point & $\mathbf{1}$ & $\mathbf{2}$ & $\mathbf{3}$ & $\mathbf{4}$ & Totals & Ratings \\
\hline 1. CONVENIENCE & 3 & 0 & 1 & 4 & 1 \\
41. Not collected right away led to "cramming" & 2 & 1 & 2 & 5 & 2 \\
44. Time: takes too much & 0 & 0 & 1 & 1 & 2 \\
47. Printing costs & 1 & 4 & 1 & 6 & 2 \\
49. Hard to obtain notes/ write TA if Absent & & & & $\mathbf{4 5}$ & \\
2. COGNITIVE LOAD & 2 & 4 & 2 & 8 & 3 \\
42.If not done right away, & & & & & \\
HARD to understand even with notes & 3 & 0 & 2 & 5 & 3 \\
43. Number of submissions due & 5 & 0 & 1 & 6 & 3 \\
45. Amount of Writing too much/tedious & 0 & 1 & 0 & 1 & 4 \\
46. Writing makes incorrect info stick & 1 & 4 & 0 & 5 & 4 \\
48. Creating text from notes difficult & 4 & 3 & 1 & 1 & 8 & 4 \\
51. Rubric and Grading Changing/difficult/confusing & 0 & 1 & & 1 & 3 \\
52. Taking notes too difficult/inefficient & 3 & 1 & 3 & 7 & 3 \\
53. Hard make connections to other material/Life & 2 & 1 & 0 & 2 & 4 & 3 \\
54. Hard to learn what's important from EMAIL & & & & \\
\hline
\end{tabular}




\section{MECHANICS}

28

50. Expectations not made clear

55. Feedback not timely

56. Feedback and grading on Writing format, not CONTENT- forcing re-do

57. Less effective Study tool for me due to mandatory format
0

4

$\begin{array}{lll}2 & 2 & 2 \\ 1 & 0 & 2 \\ 1 & 3 & 5\end{array}$

6

4

4

4

$\begin{array}{lllll}30 & 29 & 28 & 4 & 89\end{array}$

\section{Conclusions}

This study showed the effectiveness of Takeaways in high school science courses, the scalability of the Takeaway technique and its potential for making many science and social science courses more effective for the range of students, including novice students, who need to be success in such courses. Since a rival treatment (i.e., the control post-class writing technique) was used in this study, this study showed directly that the Take-away is the instructional component that produces the effects and gains observed, as opposed to other factors, and especially so in relation to the first pilot study where the causal evidence was more indirect and a triangulation and weight of evidence design was used. Students in this study, as well as the first study, moreover, self-reported relatively the same benefits of doing Take-aways, and these reported benefits were consonant with the theory of Take-aways outlined in the first study and summarized here. Even the negatives of doing Take-aways were similar between the two studies which is strong additionally evidence for the validity, claims and interpretations of the two studies which should be seen and interpreted as a unit rather than separately because of all of the alternative factors "rule-out" evidence that was generated in the first study (e.g., aptitude, writing ability, prior achievement levels and so on). This study and the first study together provide strong and varied exploratory evidence for the theory and effectiveness of the Take-away technique. Further, it is critically important to remember that all of the effects that were observed in these two studies were the minimum baseline effects of using the Take-away Technique without the teacher providing corrective feedback on them, or changing their difficulty levels, or altering instruction as instruction progressed based upon the instructional effectiveness information the Take-aways provide the teacher; namely, without additional work or burden for the teacher or the instructor. These two studies show the effects teachers and instructors can get from using the Take-away technique doing essentially little different in their teaching, classrooms or courses. It is fairly obvious, however, that all of the effects of Take-aways observed in these two studies may be significantly enhanced and even accelerated by providing corrective feedback to students on their Take-aways and/or altering instruction based on the real time effectiveness evidence they provide, all of which are the kinds of further research needed on the Take-away technique.

The importance of the back-end of the learning process is here again emphasized by the results of this study (as well as the first) and the theory of the Take-away, which is built on a view of how performances under conditions of moderate/optimal anxiety by students in terms of creating their own schemas and long term memory structures enhances learning and long term retention. The Take-away technique does not promote learned helplessness (Maier \& Seligman, 1976), but in fact helps such behaviors in their many different forms to be unlearned on a continuous and ongoing basis. The Take-away technique is demanding and labor intensive, but given the intense pressures and accountabilities to improve achievement and to close achievement gaps between different priority groups today that would seem to be a small price for the achievement gains and gap closings obtained. The Take-away technique also embodies a cognitive theory of learning and the development of self-directed and cognitively active learning character that is not highly prescriptive and does not "do everything for the learner," and in fact makes the learner do a great deal of the learning work her and himself in a manner that is inescapable (as the student soon learns), as it is the learner who must produce the Take-away and not the instructor or instructional agent. This view and theory of learning also does not see anxiety, conflict and cognitive dissonance as a "bad thing" and something to be avoided, but in fact sees it as a "good thing" and to be encouraged if optimized and kept in the productive zone (Mandler, 1989; and Erikson, 1993), as it enhances learning and the development of essential meta-cognitive skills (Reivich \& Shatte, 2002; and Green \& Azvedo,2007), as well as the formation and strengthening of long term memories (Meeter \& Murre, 2004). This view of learning, instruction and the learner is antithetical to the prevailing views in many areas, but particularly in the area of science and mathematics learning and particularly at the lower and introductory educational levels. However, it is this very different view of 
learning, instruction and the learner that is the very basis of the Take-away technique, which has produced superior achievement, meta-cognitive skill gains and understanding, and superior affective outcomes also in two studies now with more studies currently underway. Effectively using the Take-away technique for maximum gains, therefore, take a shifting of several of one's views and beliefs about learning, instruction and students, and understanding that doing less for the learner in certain defined and highly focused ways is actually doing more for the learner and in fact much more.

\section{References}

Adams, W. K., Perkins, K. K., Podolefsky, N. S., Dubson, M., Finkelstein, N. D., \& Wieman, C. E. (2006). New instrument for measuring student beliefs about physics and learning physics: the Colorado learning attitudes about science survey. Physical Review Special Topics-Physics Education Research, 2(1), 1-14. http://dx.doi.org/10.1103/PhysRevSTPER.2.010101

Ashcraft, D. (2001). Human memory and cognition (3rd ed). New York: Pearson.

Ausubel, D. (1976). Educational psychology: a cognitive view. New York: Holt, Rinehart, \& Winston.

Beichner, R. J., Saul, J. M., Allain, R. J., Deardorff, D. L., \& Abbott, D. S. (2007). Student-centered activities for large enrollment undergraduate programs (scale-up) project. Research-Based Reform of University Physics, 1(1), 2-39. Retrieved from http://www.per-central.org/per_reviews/volume1.cfm

Bruning, R., G., Schraw, M. \& Norby, M. (2010). Cognitive Psychology and Instruction (5th ed). New York: Pearson.

Carifio, J. (2005). An integrated information processing theory of learning. Proceedings of the Eighth International History, Philosophy \& Science Teaching Conference, Leeds, England (pp. 101-173). Retrieved from http://www.ihpst2005.leeds.ac.uk/papers/Carifio.pdf

Carifio, J. (2010). Increasing Undergraduate Students' Higher Order Learning and Course Achievement Through the Takeaway Technique. Paper presented at the annual conference of the New England Educational Research Associate, Hartford, CN.

Coletta, V. P., \& Phillips, J. A. (2005). Interpreting fci scores: normalized gain, preinstruction scores, and scientific reasoning ability. American Journal of Physics, 73(12), 1172-1182. http://dx.doi.org/10.1119/1.2117109

Crouch, C. H., Watkins, J., Fagan, A. P., \& Mazur, E. (2007). Peer instruction: Engaging students one-on-one, all at once. Research-Based Reform of University Physics, 1(1), 40-95. Retrieved from http://www.per-central.org/per_reviews/volume1.cfm

Dagostino, L., \& Carifio, J. (1994). Evaluative Reading and Literacy: a Cognitive View. Boston: Allyn and Bacon.

Dinsmore, D. L., Alexander, P. A., \& Loughlin, S. M. (2008). Focusing the conceptual lens on metacognition, self-regulation, and self-regulated learning. Educational Psychology Review, 20(4), 391-409. http://dx.doi.org/10.1007/s10648-008-9083-6

Erikson, E. (1993). Childhood and Society (2nd ed). New York, W.W. Norton and Company.

Eagle, M. (1997). Contributions of Erik Erikson. Psychoanalytic review, 84(3), 337-347.

Green, J., \& Azvedo, R. (2007). A theoretical review of Winne and Hadwin's model of self-directed learning: New perspectives and directions. Review of Educational Research, 77(3), 334-372. http://dx.doi.org/10.3102/003465430303953

Hestenes, D., Wells, M., \& Swackhamer, G. (1992). Force Concept Inventory. The Physics Teacher, 30(3), 141-158. http://dx.doi.org/10.1119/1.2343497

Hake, R. R. (1987). Promoting student crossover to the Newtonian world. American Journal of Physics, 55(10), 878-884. http://dx.doi.org/10.1119/1.14945

Hake, R. R. (1998a). Interactive-engagement versus traditional methods: A six-thousand-student survey of mechanics test data for introductory physics courses. American Journal of Physics, 66(1), 64-78. http://dx.doi.org/10.1119/1.18809

Hake, R. R. (1998b). Interactive-engagement methods in introductory mechanics courses. Retrieved from http://www.physics.indiana.edu/ hake/

Hautau, B., Turner, H. C., Carroll, E., Jaspers, K., Parker, M., Krohn, K., \& Williams, R. L. (2006). Differential 
daily writing contingencies and performance on major multiple-choice exams. Journal of Behavioral Education, 15(4), 256-273. http://dx.doi.org/10.1007/s10864-006-9031-9

Hestenes, D., \& Wells, M. (1992). A mechanics baseline test. Physics Teacher, 30(3), 159-166. http://dx.doi.org/10.1119/1.2343498

Hestenes, D., \& Halloun, I. (1995). Interpreting the force concept inventory. Physics Teacher, 30(11), 502-505. http://dx.doi.org/10.1119/1.2344278

Hewson, P., \& Hewson, M. (1984). The role of conceptual conflict in conceptual change and the design of science. Instructional Science, 13(1), 1-13. http://dx.doi.org/10.1007/BF00051837

Hubbs, D., \& Brand, C. F. (2005). The paper mirror: Understanding reflective journaling. Journal of Experiential Education, 28(1), 60-71. Retrieved from http://www.aee.org/publications/jee/abstracts

Keys, C. W., Hand, B., Prain, V., \& Collins, S. (1999). Using the science writing heuristic as a tool for learning from laboratory investigations in secondary science. Journal of Research in Science Teaching, 36(10), 1065-1084. http://dx.doi.org/10.1002/(SICI)1098-2736(199912)36:10<1065::AID-TEA2>3.0.CO;2-I

Kintsch, W. (1998). Comprehension: A paradigm for cognition. New York: Cambridge University Press.

Laws, P. W. (1991). Calculus-based physics without lectures. Physics Today, 44(12), 24-31. http://dx.doi.org/10.1063/1.881276

Lorenzo, M., Crouch, C. H., \& Mazur, E. (2006). Reducing the gender gap in the physics classroom. American Journal of Physics, 74(2) 118-122. http://dx.doi.org/10.1119/1.2162549

Mandler, G. (1989). Affect and learning: Causes and consequences of emotional interaction. In D. B. McLeod \& V. M. Adams (Eds), Affect and mathematical problem solving: A new perspective. NY: Springer-Verlag. http://dx.doi.org/10.1007/978-1-4612-3614-6_1

Meeter, M., \& Murre, J. (2004). Consolidation of long term memory: evidence and alternatives. Psychological Bulletin, 130(6), 843-857. http://dx.doi.org/10.1037/0033-2909.130.6.843

Maier, S., \& Seligman, M., (1976). Learned helplessness: theory and evidence. Journal of Experimental Psychology, 105, 3-46. Retrieved from http://psycnet.apa.org/journals/xge/105/1/3/

Mestre, J. P. (1994). Cognitive aspects of learning and science teaching. In Fitzsimmons, S. J., \& Kerpelman, L. C. (Eds.), Teacher Enhancement for Elementary and Secondary Science and Mathematics: Status, Issues, and Problems. (3.1-3.53). Washington, DC: National Science Foundation. Retrieved from http://www.eric.ed.gov/ERICWebPortal/search/detailmini.jsp?_nfpb=true\&_\&ERICExtSearch_SearchValue _0=ED372963\&ERICExtSearch_SearchType_0=no\&accno=ED372963

Mestre, J. P. (2005). Facts and myths about pedagogies of engagement in science learning. Association of American Colleges and Universities: Peer Review, 7(2), 1-4. Retrieved from http://www.aacu.org/peerreview/pr-wi05/pr-wi05contents.cfm

Neisser, U., \& Hyman, I., (1999). Memory observed: remembering in natural contexts (2nd ed). New York: Worth.

Otero, V. K., \& Gray, K. E. (2008). Attitudinal gains across multiple universities using the physics and everyday thinking curriculum. Physical Review Special Topics-Physics Education Research, 4(2), 1-7. http://dx.doi.org/10.1103/PhysRevSTPER.4.020104

Pinker, S (2009). The Computational Theory of Mind. Retrieved from http://www.nibipedia.com/app.html?view=video\&channel=nibipedia\&playlist=BA44F18CE32DB566\&vid eoId=LVrb5ClvDho

Pressley, M. (2002). Metacognition and self-regulated comprehension. In A. E. Farstrup, \& S. J. Samuel (Eds.), What research has to say about reading instruction (3rd ed., pp. 291-309). Newark, DE: International Reading Association.

Piburn, M., Sawada, D., Falconer, K., Turley, J., Benford, R., \& Bloom, I. (2000). Reformed teaching observation protocol. Retrieved from http://purcell.phy.nau.edu/AZTEC/rtop/

Piburn, M., Sawada, D., Judson, E., Falconer, K., Turley, J., Benford, R., \& Bloom, I. (2002). Measuring reform practices in science and mathematics classrooms: The reformed teaching observation protocol. School Science and Mathematics, 10 (6), 245-253. Retrieved from http://onlinelibrary.wiley.com/doi/10.1111/j.1949-8594.2002.tb17883.x/abstract 
Redish, E. F. (1994). Implications of cognitive studies for teaching physics. American Journal of Physics, 62(6), 796-803. http://dx.doi.org/10.1119/1.17461

Redish, E. F., Saul, J., \& Steinberg, R. N. (1998). Student expectations in introductory physics. American Journal of Physics, 66, 212-224. http://dx.doi.org/10.1119/1.18847

Reivich, K. \& Shatte, A. (2002). The resilience factor: essential skills for overcoming life's inevitable obstacles. New York: Broadway Books.

Schunk, D. (2011). Learning theories: an educational perspective (6th ed.). New York: Pearson.

Schneider, W., \& Pressley, M. (1997). Memory development between 2 and 20. Mahwah, NJ: Erlbaum.

Spielberger, C. (1972). Anxiety: Current trends in theory and research. Orlando FL, Academic Press.

van Dijk, T. A. (2006). Discourse, Interaction and Cognition. Special Issue, Discourse Studies, 8(1), 159-177. http://dx.doi.org/10.1177/1461445606059565

Vygotsky, L. S. (1978). Mind in society: The development of higher psychological processes. Harvard University Press.

Zimmerman, B. (1994). Dimensions of academic self-regulation: A conceptual framework for education. In D.H. Schunk and B.J. Zimmerman, (Eds), Self-regulation of learning and performance: Issues and educational implications (pp. 3-21), Erlbaum, Hillsdale, NJ. 